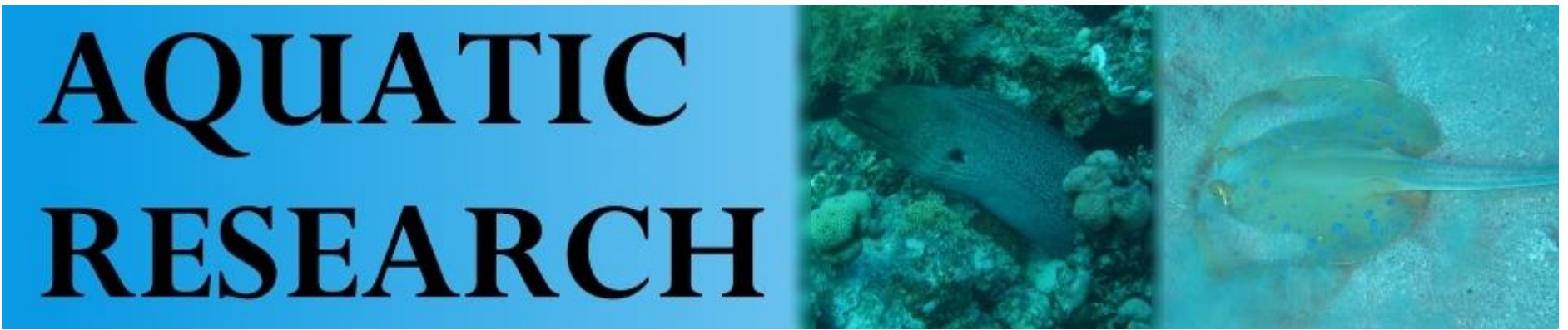

\title{
EFFECT OF SAVORY EXTRACT SUPPLEMENTATION ON SOME PRODUCTIVE TRAITS AND ECONOMIC EFFICIENCY OF COMMON CARP (Cyprinus carpio L.)
}

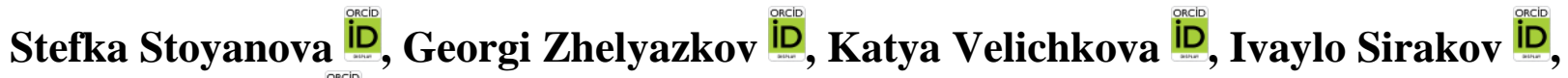 \\ Yordan Staykov iD
}

Cite this article as:

Stoynova, S., Zhelyazkov, G., Velichova, K. Sirakov I., Staykov, Y. (2018). Effect of Savory Extract Supplementation on Some Productive Traits and Economic Efficiency of Common Carp (Cyprinus carpio L.). Aquatic Research, 1(3), 110-114. DOI: 10.3153/AR18012

Department of Biology and Aquaculture, Faculty of Agriculture, Trakia University, Students Campus, 6014 Stara Zagora, Bulgaria

Submitted: 23.02 .2018

Accepted: 09.03.2018

Published online: 12.03 .2018

Correspondence:

Stefka STOANOVA

E-mail:

st_stoyanova@mail.bg

(C) Copyright 2018 by ScientificWebJournals Available online at

http://aquatres.scientificwebjournals.com

\begin{abstract}
The purpose of this study is to evaluate the effect of a dietary savory extract supplement on the survival rate, growth performance, feed conversion ratio and economic efficiency of common carp (Cyprinus carpio L.) reared in a recirculation system. Thirty-two carps were allotted into two experimental variants, each of them comprising two replications with 8 fish in a group. The average initial live weight of fish from both replications from the control group (CG) and experimental group (EG) was $866.56 \pm 113.99 \mathrm{~g}$ and $866.81 \pm 119.10 \mathrm{~g}$, respectively $(\mathrm{p}>0.05)$. They were kept in concrete tanks with efficient water volume of $0.8 \mathrm{~m}^{3}$, elements of the recirculation system. Carps were fed pelleted carp feed with $25 \%$ crude protein, produced with pellet size of $6 \mathrm{~mm}$. The feed of fish from the EG was supplemented with $1 \%$ powdered savory extract, after lubricating the pellets with $5 \mathrm{ml}$ sunflower oil per $100 \mathrm{~g}$ feed. Control carp received the same amount of sunflower oil-lubricated feed. The daily ration of fish from both replications was $1.8 \%$ of their live weight. The experiment duration was 45 days. Survival rates during the experiment showed 100\% survival in carps, supplemented with $1 \%$ savory extract as well as in control fish. The average individual weight gain of carps from the two EG replications (supplemented with $1 \%$ savory extract) was $154.63 \pm 28.39 \mathrm{~g}$, which was higher than that of controls by $57.18 \%$ (Table 3 ), as the differences were statistically significant ( $p<0.001)$. At the end of the trial, the analysis of consumed feed amount showed that feed conversion ratio in the group supplemented with $1 \%$ savory extract was $2.25 \pm 0.43$ e.g. by $67.11 \%$ lower than that of control group, as the differences were statistically significant $(\mathrm{p}<0.001)$. The group that received $1 \%$ savory extract exhibited better economic conversion ratio (1.98), by $42.42 \%$ lower than that of the non-supplemented group.
\end{abstract}

Keywords: Common carp, Savory extract, Feed conversion ratio, Weight gain, Survival rate, Economic efficiency 


\section{Introduction}

The monitoring of fish nutrition and the amount of unconsumed feed help optimize feeding and economic management of the farm, improve profitability and reduce the negative impact of fish production on the environment (Atanasov et al., 1999). In recent years, the fish feed has included a variety of nutritional supplements to improve its quality. Furthermore, dietary additives should improve feed utilization. Conducted experiments with various types of feed supplements (Jayaprakash and Euphrasia, 1996; Polat and Beklevik, 1999; Citarasu et al., 2003; El-Dakar et al., 2007). One of the requirements of this approach is the use of organic ingredients in the production of feed for various species, including biologically based immune-stimulants, which improve the health status and reduce the mortality of cultivated hydrobiones (Raa 1996). They are a requirement of organic aquaculture and are widely used in the feed industry (Galleoti, 1998; Best, 2002; Li and Gatlin, 2004; Costa - Pierce, 2010). The use of plant extracts as supplements in fish feed is harmless to fish and the environment (Gabor et al., 2010; Gabor et al., 2011). At present, interest in modern standards and requirements related to organic aquaculture is increasing in the European Union, the US and other countries (Staykov et al., 2005). The ultimate success in aquaculture depends on thorough knowledge of biology, controlling the production cycle and maintain a close link between nutrition and health status (Wedemeyer 1997, Staykov et al., 2005). Many authors have described the beneficial effects of the use of food additives on the survival and productivity of fish and treatment of various infectious diseases and parasites in fish (Zhou and Li 2004; Culjak et al. 2006; Stratev et al., 2018). However, studies that have assessed the effect of phytoadditives on growth indicators and feed conversion parameters for different farmed fish species are few.

The savory (Satureja hortensis) is a species of the Lamiaceae family, grown in warm temperate regions of the northern hemisphere, whose fresh and dried leaves are used as a spice. They are known to have antimicrobial, antitumor, antimutagenic, antigenotoxic, analgesic, antispasmodic, antiinflammatory, angiogenic, antiparasitic, antiplatelet, and antioxidant properties (Charles, 2012). The influence of savory (Satureja hortensis) on the gut micro flora, immune response and blood biochemical parameters of juveniles carp (Cyprinus carpio) is reported by Mousavi et al., (2016).

The purpose of this study is to evaluate the effect of a dietary savory extract supplement on the survival rate, growth performance, feed conversion ratio and economic efficiency of common carp (Cyprinus carpio L.) reared in a recirculation system.

\section{Materials and Methods}

Thirty-two common carps were allotted into two experimental variants, each of them comprising two replications, with 8 fish in a group. The average initial live weight of carps from the control group (CG) and experimental group (EG) was $866.56 \pm 113.99 \mathrm{~g}$ and $866.81 \pm 119.10 \mathrm{~g}$, respectively. Fish were kept in concrete tanks with efficient water volume of $0.8 \mathrm{~m}^{3}$, elements of the recirculation system. They were fed pelleted carp feed with $25 \%$ crude protein, produced by the Top mix company, with pellet size of $6 \mathrm{~mm}$. The feed of fish from the EG was supplemented with $1 \%$ powdered savory extract after lubricating the pellets with 5 $\mathrm{ml}$ sunflower oil per $100 \mathrm{~g}$ feed. Control carps received the same amount of sunflower oil-lubricated feed. The nutrient content in the pelleted feed of both groups' common carp (Cyprinus carpio L.) is as follows presented:

$>$ CG: Crude protein- 25\%; Crude lipids $-3.10 \%$; Crude fiber -6 \%; Crude ash - 8\%; P- 1.04\%; ME$11.10 \mathrm{MJ} / \mathrm{kg}$; Vitamin A-4800 IU/kg; Vitamin D-900 $\mathrm{IU} / \mathrm{kg}$;

$>$ EG: Crude protein- 25\%; Crude lipids $-3.10 \%$; Crude fiber -6 \%; Crude ash - 8\%; P- 1.04\%; Savory extract 1 $\%$; ME- 11.10MJ/kg; Vitamin A-4800 IU/kg; Vitamin D-900 IU/kg.

The daily ration of fish from both replications was $1.8 \%$ of their live weight and they were fed three times per day. The experiment duration was 45 days.

- The hydrochemical parameters in the recirculating system of the common carp (Cyprinus carpio L.) were determined using methods adapted for fish-farming and MultiLine P4 as follows: Quantity of the dissolved oxygen $/ \mathrm{mg} . \mathrm{l}^{-1} ; \mathrm{pH}$; Electrical conductivity/ $\mu \mathrm{S} . \mathrm{cm}^{-1}$ and BDS EN 27888; Quantity of nitrates, mg.1 ${ }^{-1}$ - BDS 17.1.4.12:1979; Quantity of nitrites, mg. $\mathrm{l}^{-1}-$ BDS ISO 26777:1997.

The above water parameters were daily measured.

- The economic efficiency analyses of the savory extract supplementation in the diet of carp (Cyprinus carpio L.), cultivated in recirculation system, data for feed conversion ratio, weight gain and survival rate were used. Comparisons of these traits were made between the fish of the different experimental groups and the costs for the pelleted feed were determined. The price cost for $1 \mathrm{~kg}$ weight gain of the fish, cultivated in recir- 
culation systems was determined. The economic conversion ratio (ECR) was calculated, using the following equation (Piedecausa et al., 2007):

$>\quad \mathrm{ECR}=$ Cost of Diet $\mathrm{x}$ Feed Conversion Ratio (FCR)

Statistical evaluation of the data was done by STATISTICA 6.0 software (StatSoft Inc., 2002).

\section{Results and Discussion}

During the trial period the hydrochemical parameters in the recirculation system were maintained in the optimal limits for common carp. Their values during the experiment are presented in Table 1.
The water temperature for the two experimental groups was $24.00 \pm 1.48^{\circ} \mathrm{C}$. Dissolved oxygen content from both replications of control and experimental variants was $6.63 \pm 0.32$ $\mathrm{mg} . \mathrm{l}^{-1}$ and $6.68 \pm 0.36 \mathrm{mg} . \mathrm{l}^{-1}$, respectively, but differences were not significant $(\mathrm{p}>0.05)$. Water $\mathrm{pH}$ from both replications of CG and EG was $7.66 \pm 0.24$ and $7.64 \pm 0.21$, respectively, as no significant differences between the replicates were found ( $p>0.05)$. Electric conductivity of water during the experiments was $675 \pm 25.00 \mu \mathrm{S} . \mathrm{cm}^{-1}$.

The results of Table 2 shows fish production parameters in both experimental groups and economic efficiency of common carp.

Table 1. Water parameters in the recirculation system during the experiment with common carp

\begin{tabular}{|c|c|c|c|c|}
\hline \multirow{2}{*}{ Parameter } & \multirow{n}{*}{$\mathbf{n}$} & $\mathbf{C G}$ & $\mathbf{E G}$ & \multirow{2}{*}{$\begin{array}{c}\text { Optimum values (Reg- } \\
\text { ulation No 4/2000) }\end{array}$} \\
\cline { 3 - 5 } & & $\bar{x} \pm \mathrm{SD}$ & $\bar{x} \pm \mathrm{SD}$ & $22.0-26.0$ \\
\hline Temperature, ${ }^{\circ} \mathrm{C}$ & 45 & $24.00 \pm 1.48$ & $24.00 \pm 1.48$ & $>5$ \\
\hline Dissolved oxygen, ${\mathrm{mg} . \mathrm{l}^{-1}}^{\mathrm{pH}}$ & 45 & $6.63 \pm 0.32$ & $6.68 \pm 0.36$ & $6.5-8.5$ \\
\hline $\mathrm{pH}$ & 45 & $7.66 \pm 0.24$ & $7.64 \pm 0.21$ & - \\
\hline $\begin{array}{c}\text { Electric conductivity, } \\
\mu \text { S.cm }\end{array}$ & 45 & $675 \pm 25.00$ & $675 \pm 25.00$ & - \\
\hline
\end{tabular}

Table 2. Fish production parameters and economic efficiency of common carp, grown in recirculation system

\begin{tabular}{|l|c|c|c|}
\hline \multirow{2}{*}{ Parameter } & \multirow{2}{*}{$\mathbf{n}$} & CG & EG \\
\cline { 3 - 4 } & & $\bar{x} \pm \mathrm{SD}$ & $\bar{x} \pm \mathrm{SD}$ \\
\hline Initial body weight, $\mathrm{g}$ & 16 & $866.56 \pm 113.99$ & $866.81 \pm 119.10$ \\
\hline Final body weight, g & 16 & $964.94 \pm 92.04$ & $1021.44 \pm 118.28$ \\
\hline Survival rate, \% & 16 & 100 & 100 \\
\hline Average individual weight gain, $\mathrm{g}$ & 16 & $98.38 \pm 25.63$ & $154.63 \pm 28.39^{* * * *}$ \\
\hline FCR & 16 & $3.76 \pm 1.39$ & $2.25 \pm 0.43^{* * *}$ \\
\hline ECR & & 2.82 & 1.98 \\
\hline \multicolumn{2}{|r}{$* * * \mathrm{p} \leq 0.001$} & &
\end{tabular}


The average initial live weight of carps from both replications of control and experimental variants was 866.56 $\pm 113.99 \mathrm{~g}$ and $866.81 \pm 119.10 \mathrm{~g}$, respectively, but differences were not statistically significant $(p>0.05)$. By the end of the experiment, there was a tendency to higher average live weight of fish, fed with $1 \%$ savory extract supplemented pellets $-1021.44 \pm 118.28 \mathrm{~g}$ vs $964.94 \pm 92.04 \mathrm{~g}$ in control fish $(\mathrm{p}>0.05)$.

Survival rates during the experiment showed $100 \%$ survival in fish supplemented with $1 \%$ savory extract as well as in control carps.

The average individual weight gain of fish from the two EG replications (supplemented with $1 \%$ savory extract) was $154.63 \pm 28.39 \mathrm{~g}$ which was higher than that of controls by $57.18 \%$ (Table 2 ), as the differences were statistically significant $(\mathrm{p}<0.001)$.

At the end of the experiment, it was calculated that feed conversion ratio in experimental carps, supplemented with $1 \%$ savory extract, was $2.25 \pm 0.43$ on the average, e.g. by $67.11 \%$ lower than that of control group, as the differences were statistically significant $(\mathrm{p}<0.001)$ (Table 2$)$.

The better utilization of the pelleted feed supplemented with $1 \%$ savory extract had a beneficial effect on the growth performance of experimental carps. In the beginning of the trial, the body weight of all carps was similar were similar $866.56 \pm 113.99 \mathrm{~g}$ and $866.81 \pm 119.10 \mathrm{~g}(\mathrm{p}>0.05)$. At the end, supplemented fish tended to have insignificantly higher average live weight than controls whose live weight were by $5.86 \%$ lower $(\mathrm{p}>0.05)$ (Table 2 ). These results confirm Mousavi et al. (2016), whose reported better indicators of the gut microflora, immune response and blood biochemical parameters by adding $1 \%$ savory powder to juveniles carp feed. The results obtained in these studies are probably due to improved metabolism of nutrients in fish that receive savory extract.

The chosen experimental period was comparatively short, but some tendencies were established in current study. More experiments with long trial period were needed in the future to confirm the received results.

In the Table 2 are presented and the results of the economic conversion ratio of the used pelleted feed. Its price was 750 BGN per ton, VAT excluded for CG. To this feed price, the costs for the savory extract supplement should be added, which made the pellets of the experimental group more expensive by $130 \mathrm{BGN}$ per ton, VAT excluded.
The group that received $1 \%$ savory extract exhibited better economic conversion ratio (1.98), by $42.42 \%$ lower than that of the non-supplemented group.

\section{Conclusion}

The study showed that the savory extract might successfully be used as a feed additive to the diet of common carp. Its supplementation to the pellets influenced positively the growth, did not have negative effect on the survival rate of the fish, enhanced the weight gain, reduced the feed conversion ratio, as well as the economic conversion ratio.

\section{References}

Atanasov, V., Staykov, Y., Mitev J. (1999). Biochemical and biological characteristics of Tilapia fingerlings reared at different stock densities. Bulgarian Journal of Agricultural Science, 5, 655-658.

Best, P. (2002). Tracking consumer desires: towards total traceability of feed and food. Feed International, 23(2), 4-8.

Charles, D.J. (2012). Savory. In: Antioxidant Properties of Spices, Herbs and Other Sources. Springer, New York, NY USA, 531-536.

Citarasu, T., Venket, R.K., Sekar, J.R., Babu, M., Marian, M.P. (2003). Influence of the antibacterial herbs, Solanum trilobatum, Andrographis paniculata and Psoralea corylifolia on the survival, growth and bacterial load of Penaeus monodon post larvae. Aquaculture International, 11, 583-595.

Costa-Pierce, B.A. (2010).Sustainable Ecological Aquaculture Systems: The Need for a New Social Contract for Aquaculture Development Source. Marine Technology Society Journal, 44(3), 88-112.

Culjak, V., Bogut, G., Has-Schon, E., Milakovic, Z., Canecki, K. (2006). Effect of Bio-Mos on performance and health of juvenile carp. In: Nutrition and biotechnology in the feed and food industries: Alltech's 22nd annual symposium, Lexington, KY, US.

El-Dakar, A.Y., Shalaby, S.M., Saoud, I.P. (2007). Assessing the use of a dietary probiotic/prebiotic as an enhancer of spinefoot rabbitfish Siganus rivulatus survival and growth. Aquaculture Nutrition, 13(6), 407412. 
Gabor, E., Şara, A., Barbu, A. (2010). The effects of some Phyto-additives on growt, health and meat quality on different species of fish. Animal Sciences and Biotechnologies, 43(1), 61-65.

Gabor, E., Şara, A., Molnar, F., Benţea, M. (2011). The influence of some phytoadditives on growth performances and meat quality in rainbow trout (Oncorhynchus mykiss). Animal Science and Biotechnologies, 44(2), 12-18.

Galeotti, M. (1998). Some aspects of the application of immunostimulants and a critical review of methods for their evaluation. Journal of Applied Ichthyology, 14(34), 189-199.

Jayaprakash, V., Euphrasia, J. (1996). Growth performance of Labeo rohita (Han.) to Livol (IHF-1000), a herbal product. Proceedings of the National Academy of Sciences, B63, 1-10.

Li, P., Gatlin, D.M. (2004). Dietary brewer's yeast and the prebiotic Grobiotic (TM) AE influence growth performance, immune responses and resistance of hybrid striped bass (Morone chrysops x M. saxatilis) to Streptococcus iniae infection. Aquaculture, 231, 445-456.

Mousavi, E., Mohammadiazarm, H., Mousavi, S.M., Ghatrami, E.R. (2016). Effects of inulin, savory and onion powders in diet of juveniles carp Cyprinus carpio (Linnaeus 1758) on gut micro flora, immune response and blood biochemical parameters. Turkish Journal of Fisheries and Aquatic Sciences, 16, 831-838.
Polat, A., Beklevik, G. (1999). The importance of betaine and some attractive substances as fish feed additives. In: Feed Manufacturing in the Mediterranean Region. Recent Advances in Research and Technology, 217220.

Raa, J. (1996). The use of immunostimulatory substances in fish and shellfish farming. Reviews in Fish Biology and Fisheries, 4(3), 229-288.

Staykov, Y, Spring, P., Denev, S.A. (2005). Influence of dietary Bio-Mos on growth, survival and immune status of rainbow trout (Salmo gairdneri irideus $G$.) and common carp (Cyprinus carpio L.). In: Nutritional Biotechnology in the Feed and Food Industries. (Eds. T.P. Lyons, and K. Jackues). Nottingham University Press, Nottingham, UK. 333-343.

Stratev, D., Zhelyazkov, G., Noundou, X.S., Krause, R.W.M. (2018). Beneficial effects of medicinal plants in fish diseases. Aquaculture International, 26, 289308 .

Wedemeyer, G.A. (1997). Effects of rearing conditions on the health and physiological quality of fish in intensive culture. Fish Stress and Health in Aquaculture, 35-73.

Zhou, X., Li, L. (2004). The effect of Bio-Mos on intestinal microflora and immune function of juvenile Jian carp (Cyprinus carpio). In: Nutritional Biotechnology in the Feed and Food Industries, Proceedings of Alltech's 20th Annual Symposium (Suppl.1: Abstracts of posters presented). Lexington, KY, May 24-26, p. 109. 